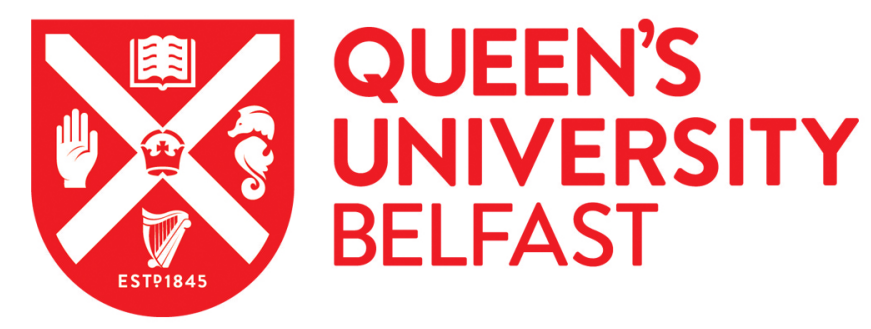

\title{
Validating clinical practice guidelines for the management of febrile infants presenting to the emergency department in the UK and Ireland
}

\author{
Waterfield, T., Lyttle, M. D., Munday, C., Foster, S., McNulty, M., Platt, R., Barrett, M., Rogers, E., Durnin, S., \\ Jameel, N., Maney, J-A., McGinn, C., McFetridge, L., Mitchell, H., Puthucode, D., \& Roland, D. (2021). \\ Validating clinical practice guidelines for the management of febrile infants presenting to the emergency \\ department in the UK and Ireland. Archives of Disease in Childhood. https://doi.org/10.1136/archdischild-2021- \\ 322586
}

Published in:

Archives of Disease in Childhood

Document Version:

Peer reviewed version

Queen's University Belfast - Research Portal:

Link to publication record in Queen's University Belfast Research Portal

Publisher rights

Copyright 2021 the authors. Published by BMJ.

This is an open access Creative Commons Attribution-NonCommercial License (https://creativecommons.org/licenses/by-nc/4.0/), which permits use, distribution and reproduction for non-commercial purposes, provided the author and source are cited.

\section{General rights}

Copyright for the publications made accessible via the Queen's University Belfast Research Portal is retained by the author(s) and / or other copyright owners and it is a condition of accessing these publications that users recognise and abide by the legal requirements associated with these rights.

Take down policy

The Research Portal is Queen's institutional repository that provides access to Queen's research output. Every effort has been made to ensure that content in the Research Portal does not infringe any person's rights, or applicable UK laws. If you discover content in the Research Portal that you believe breaches copyright or violates any law, please contact openaccess@qub.ac.uk. 
Validating clinical practice guidelines for the management of febrile infants presenting to the Emergency Department (ED) in the United Kingdom and Ireland.

Author list \& institutions

1. Thomas Waterfield

- Centre for Experimental Medicine, Wellcome Wolfson Institute of

2. Mark D Lyttle Experimental Medicine, Queen's University Belfast, Belfast, UK

- Emergency Department, Bristol Royal Hospital for Children, Bristol, UK

- Faculty of Health and Applied Sciences, University of the West of England, Bristol, UK

3. Charlotte Munday

- Emergency Department, Bristol Royal Hospital for Children, Bristol, UK

4. Steven Foster

- Emergency Department, Royal Hospital for Children, Glasgow, UK

5. Marc McNulty

- Emergency Department, Royal Hospital for Children, Glasgow, UK

6. Rebecca Platt

- Emergency Department, The Royal London Hospital - Barts Health NHS

7. Michael Barrett Trust, London, UK

- Emergency Department, Children's Health Ireland at Crumlin, Dublin, Ireland

- Women's and Children's Health, School of Medicine, University College Dublin, Ireland

- National Children's Research Centre, Crumlin, Dublin, Ireland

8. Emma Rogers

- Emergency Department, Children's Health Ireland at Crumlin, Dublin, Ireland

9. Sheena Durnin

- Emergency Department, Children's Health Ireland at Tallaght, Dublin, Ireland

10. Nida Jameel

- Discipline of Paediatrics, Trinity College, University of Dublin, Dublin, Ireland

11. Julie-Ann Maney

- Emergency Department, Royal Belfast Hospital for Sick Children, Belfast, UK

12. Claire McGinn

- Emergency Department, Royal Belfast Hospital for Sick Children, Belfast, UK

13. Lisa McFetridge

- Mathematical Sciences Research Centre, Queen's University Belfast, Belfast, UK

14. Hannah Mitchell

- Mathematical Sciences Research Centre, Queen's University Belfast, Belfast, UK

15. Deepika Puthucode

- Children's Emergency Department, Leicester Royal Infirmary, Leicester, UK

16. Damian Roland

- SAPPHIRE Group, Health Sciences, Leicester University, Leicester, UK

- Children's Emergency Department, Leicester Royal Infirmary, Leicester, UK

On behalf of Paediatric Emergency Research in the UK and Ireland (PERUKI)

Corresponding author - Thomas Waterfield, Children's Health Ireland at Temple St, Dublin, Ireland

t.waterfield@qub.ac.uk

Phone: +447872990521 


\section{Abstract}

\section{Objective}

To report the performance of Clinical Practice Guidelines (CPG) in the diagnosis of serious/invasive bacterial infections (SBI/IBI) in infants presenting with a fever to Emergency care in the UK and Ireland. Two CPGs were from the National Institutes for Health and Care Excellence (NICE guidelines NG51 and NG143) and one was from the British Society for Antimicrobial Chemotherapy (BSAC).

\section{Design}

Retrospective multicentre cohort study.

\section{Patients}

Febrile infants aged 90 days or less attending between the 31/08/2018 to 01/09/2019.

\section{Main outcome measures}

The sensitivity, specificity and predictive values of CPGs in identifying SBI and IBI.

\section{Setting}

Six paediatric emergency departments in the UK/Ireland.

\section{Results}

555 participants were included in the analysis. The median age was 53 days (IQR 32 to 70 ), $447(81 \%)$ underwent blood testing, and $421(76 \%)$ received parenteral antibiotics. There were five participants with bacterial meningitis (1\%), seven with bacteraemia (1\%) and $66(12 \%)$ with urinary tract infections. The NICE NG51 CPG was the most sensitive $-1.00(95 \% \mathrm{Cl} 0.95$ to 1.00). This was significantly more sensitive than NICE NG143 - 0.91 (95\% Cl 0.82 to 0.96 , $p=0.0233)$ and BSAC - $0.82(95 \% 0.72$ to $0.90, p=0.0005)$. NICE NG51 was the least specific $0.0(95 \% \mathrm{Cl} 0.0$ to 0.01$)$ and this was significantly lower than the NICE NG143 $-0.09(95 \% \mathrm{Cl}$ 0.07 to $0.12, p<0.0001)$ and BSAC $-0.14(95 \% \mathrm{Cl} 0.1$ to $0.17, \mathrm{p}<0.0001)$.

\section{Conclusion}

None of the studied CPGs demonstrated ideal performance characteristics. CPGs should be improved to guide initial clinical decision-making. 


\section{Introduction}

Young febrile infants (90 days of age and younger) are at high risk of serious and invasive bacterial infections (SBI/IBI), with approximately $10-20 \%$ having either bacteraemia, meningitis or urinary tract infection [1-4]. Correctly identifying those with $\mathrm{SBI} / \mathrm{IBI}$ is challenging, and no single laboratory test can reliably identify the diagnosis [4-13]. These challenges, combined with the higher risk of $\mathrm{SBI} / \mathrm{IBI}$, has led to a cautious approach to the assessment and initial management of these infants in the UK and Ireland, where the majority undergo blood testing, lumbar puncture, administration of parenteral antibiotics and admission

Internationally, there are a number of validated approaches to the assessment and management of febrile infants including the StepByStep and PECARN clinical practice guidelines (CPGs) [3,4]. These CPGs describe a tailored approach to the management of febrile infants dependent upon age, clinical appearance, and laboratory results. Using these, some infants can be identified as low risk and discharged without lumbar puncture and parenteral antibiotics. However these CPGs cannot currently be widely utilised or validated in the UK \& Ireland as they require the measurement of blood procalcitonin, a test that is not widely available in this setting $[3,4]$.

In the UK and Ireland two CPGs from the National Institute for Health and Care Excellence (NICE) which do not utilise procalcitonin are therefore widely used to guide initial assessment and management of febrile infants $[14,15]$. These are "Sepsis: recognition, diagnosis and early management" [NICE NG51], and "Fever in under 5s: assessment and initial management" [NICE NG143] [14,15]. These differ in approach despite both applying to febrile young infants. NG51 advises all febrile infants under 3 months of age should be treated for suspected sepsis, irrespective of their clinical appearance and laboratory results. NICE NG143 advocates a tailored approach based on clinical appearance and laboratory results advising that parenteral antibiotics are given to all infants younger than 1 month with fever, all infants aged 1-3 months with fever who appear unwell and all infants aged 1-3 months with WBC less than $5 \times 109 /$ litre 
or greater than $15 \times 109 /$ litre.

A third UK CPG has been derived by the British Society for Antimicrobial Chemotherapy (BSAC) which also advocates a tailored approach. The BSAC guidance advises that all infants under one month of age with a fever, all infants aged 1-3 months with a fever who appear unwell and all infants with positive urinalysis or CRP $>20 \mathrm{mg} / \mathrm{l}$ received parenteral antibiotics [16].

The aims of this retrospective observational study were to report rates of SBI/IBI amongst febrile infants under 90 days of age presenting to UK and Irish hospitals, to validate CPGs in use in this setting, and to describe predictors of SBI/IBI.

\section{Methods}

Study design

The protocol is available at www.clinicaltrials.gov and adheres to the TRIPOD statement for prediction model validation (TRIPOD checklist in supplementary material) [17]. This retrospective multicentre observational study was conducted at six UK and Irish tertiary paediatric Emergency Departments (ED) selected from the PERUKI network. Infants aged 90 days or younger attending between 31/08/2018 - 01/09/2019 were screened for inclusion by searching emergency clinical software databases for all infants under 90 days of age presenting with a febrile illness. Participating centres were distributed across the UK and Ireland with one centre in Northern Ireland, one in Scotland, three in England, and one in Ireland. All were paediatric hospitals with a combined annual ED census of approximately 390,000 children. Patients with a recorded fever $\left(\geq 38^{\circ} \mathrm{C}\right)$ at triage were eligible for inclusion. There were no exclusion criteria. 


\section{Outcome measures}

The primary outcome measures were

- performance accuracy of CPGs (NICE NG51, NICE NG143 and BSAC) in identifying infants with $\mid \mathrm{BI} / \mathrm{SBI}$

- performance accuracy of clinicians in identifying infants with IBI/SBI

Secondary outcomes were

- rates and types of SBI/IBI

- length of stay, procedures performed and use of antimicrobial drugs

- clinical predictors of IBI/SBI

\section{Reference standards and definitions}

Definitions were based on existing published standards $[3,4]$. IBI was defined as bacterial meningitis or bacteraemia (non-contaminant) confirmed by culture or molecular diagnostic testing of a sterile site (for example, blood or cerebrospinal fluid (CSF)). Coagulase negative Staphylococcus, Propionibacterium acnes, Streptococcus viridans, or Diphtheroides were considered contaminants. SBI was defined as urinary tract infection (UTI) with growth of $\geq 100$ $000 \mathrm{cfu} / \mathrm{mL}$ of a single organism. Abnormal urinalysis was defined as presence of leukocyte esterase, nitrite, or pyuria ( $>5$ white blood cells per high-power field [WBC/hpf]). The threshold above which C-reactive protein (CRP) was considered elevated was $20 \mathrm{mg} / \mathrm{l}$. This threshold was chosen based on the common cut-off used by current UK and International guidance [11, 13,16]. Reference standard testing was performed by technicians blinded to clinical assessment. 
Identifying missed cases of SBI/IBI.

All sites performed a check of electronic records to identify unplanned re-attendances within seven days of discharge, to determine whether any participants with SBI/IBI may have been initially discharged without treatment.

\section{Identifying clinical risk factors}

Potential predictor variables for SBI and IBI were identified by reviewing clinical features listed in the NICE CPGs [14,15], and included in the case report form (FIDO_CRF; supplementary material). These included background information (age, gender, vaccination status), duration of illness, appearance of infant, presence of signs of shock and meningitis and other symptoms (e.g. reduced conscious level, respiratory symptoms, poor feeding), initial vital signs, and blood results. The BSAC CPG was published after data collection had commenced and could not be used in the CRF development process [16]. By coincidence all of the characteristics included in the BSAC CPG were included in the CRF already.

\section{Study procedures}

The study was conducted retrospectively and only included anonymised, non-personal, routinely collected clinical data. All infants received usual care and there were no additional interventions.

\section{Data management}

Data were collected and managed using REDCap (Research Electronic Data Capture) electronic data capture tools [18]. Participants with incomplete clinical assessment data were excluded from the analysis. Prior to statistical analysis three authors (TW, LM, HM) checked completeness of data using IBM statistical package for social sciences (SPSS) version 23. Two authors (TW and CM) applied the three CPGs to the data set. Not all infants underwent blood testing. Where blood test data were not reported, multiple imputation with chained equations to create five imputed datasets was undertaken to provide imputed values. To 
minimise bias the analysis was repeated, excluding imputed data.

\section{Data analysis}

The study population's demographic characteristics, vaccination status, risk factors, parenteral antibiotic use, admission to hospital, admission to intensive care units, and survival are presented using descriptive statistics. Performance accuracy of the three CPGs and clinician practice are presented using sensitivity, specificity, negative predictive value (NPV) and positive predictive value (PPV) (with 95\% confidence intervals), and McNemar's test was used to assess difference in sensitivities and specificities between CPGs. The clinical risk factors were assessed in a stepwise approach. Initially all identified predictor variables were assessed using univariate analysis with Chi-squared/ Fisher's exact testing of categorical data, and the Mann-Whitney $U$ test for continuous data. Age-dependent predictors such as heart rate, respiratory rate and blood pressure were converted to categorical data and classified as normal or abnormal based on published normal ranges [19]. Predictor variables with a statistically significant association with $\mathrm{SBI}(p<0.20)$ were included in a binary multivariable logistic regression model. A liberal level of significance $(p<0.20)$ was chosen to avoid falsely excluding a significant variable based on univariate analysis alone. Those identified from the univariate analysis were then included in the logistic regression modelling. Empirical binary multivariable forward and backward logistic regression modelling was used to identify a best-fit model to identify children at highest risk of SBI/IBI.

\section{Office for Research Ethics Committees (OREC) and local Research Governance}

National research ethics committee approval was not necessary for this study based on the results from the Health Research Association decisions tool [20]. The study was however registered with, and approved by, research governance offices at the respective sites. 
Study registration

The study was registered at https://www.clinicaltrials.gov (trial registration: NCT04196192) on the 19th of December 2019.

\section{Findings}

A total of 1942 eligible infants were screened, of which 1379 were ineligible, 8 had incomplete data sets and 555 were included in the final analysis (Figure 1). Recruitment by site is presented in Table 1. The median age of participants was 53 days (IQR 32-70; range 1-90), and there were 325 male participants (59\%). In total 78 (14\%) participants had a confirmed SBI/IBI including $12(2 \%)$ with IBI and 66 (12\%) with UTI. The 12 participants with IBI included five (1\%) with bacterial meningitis, and seven (1\%) with bacteraemia (Tables 1 and 2).

A total of 447 participants (81\%) underwent blood testing, $328(59 \%)$ underwent a lumbar puncture (LP), and $52(9 \%)$ were discharged home without either test. Of these, three reattended, but none were subsequently diagnosed with a SBI/IBI. Fifteen (3\%) blood cultures had suspected contaminants, including Coagulase Negative Staphylococcal species (12), Streptococcus Viridans (1), and Diphtheroid (1). Of the participants that underwent phlebotomy and LP 52/447 (12\%) and 133/328 (41\%) respectively had the number of attempts recorded. The median number of attempts at intravenous cannulation was 1 (IQR 1-3), and the median number of attempts at Lumbar Puncture was 3 (IQR 1-4).

Of the 555 participants, $421(76 \%)$ received parenteral antibiotics, $79(14 \%)$ were observed without parenteral antibiotics, and $53(10 \%)$ were discharged without parenteral antibiotics. The median length of stay (LOS) of admitted participants with no confirmed SBI/IBI was 48 hours (IQR 25-69), compared to a median LOS of 72 hours (IQR 48-116) in those with SBI/IBI, a statistically significant difference $(p<0.0001)$. No participants required intensive care and all participants survived. 
Performance accuracy of the CPGs is presented in Table 3. NG51 displayed greatest sensitivity $(1.00 ; 95 \% \mathrm{Cl} 0.95-1.00)$, significantly higher than NG143 $(p=0.023)$ and BSAC $(p=0.0005)$. NG51 also demonstrated the lowest specificity $(0.0 ; 95 \% \mathrm{Cl} 0.0-0.01)$, significantly lower than NG143 and BSAC ( $p<0.0001)$. The sensitivity of clinician practice was 0.96 (95\% Cl 0.89-0.99), and specificity 0.27 (95\% Cl 0.24-0.32). Whilst the sensitivity showed no significant difference to the best performing CPG (NG51; $p=0.25)$, the specificity was significantly higher than that seen for all CPGs $(p<0.0001)$. Analyses performed with imputed values excluded $(n=12)$ were almost identical to the primary analysis (available in supplementary material). All of the infants with excluded data were well appearing infants without subsequent diagnosis of SBI/IBI.

The univariate analysis is shown in Table 4. Following multivariable analysis, receipt of vaccination in the preceding 24 hours $(p=0.031)$ and age $>28$ days $(p=0.049)$ were associated with not having a SBI/IBI. There were no cases of confirmed $S B I / I B I$ in well appearing infants presenting within 24 hours of vaccination. The median CRP, white cell count, and neutrophil counts were higher in participants with $\mathrm{SBI} / \mathrm{IBI}$ compared to those without $\mathrm{SBI}$, but there was no difference in lymphocyte counts between the two groups (Table 5).

\section{Interpretation}

This study represents the largest UK and Irish study of febrile infants presenting to Emergency Departments. The study was conducted at six different tertiary sites distributed across the UK and Ireland and likely provides a true reflection of current practices. Of the 555 included infants $78(14 \%)$ were diagnosed with a SBI/IBI including $5(1 \%)$ with bacterial meningitis and $7(1 \%)$ with bacteraemia. These values are similar to those reported by international studies [4-7].

None of the assessed CPGs performed sufficiently well. The NICE NG51 CPG was the most sensitive (1.00) but required all infants to receive parenteral antibiotics. Whilst this approach could be considered safe in the acute phase, there is increasing evidence that the excessive 
use of broad-spectrum antibiotics in infancy can alter the microbiota and contribute to longterm health complications including atopy and asthma [21-25]. A more tailored approach, if equally safe, would therefore be desirable. StepByStep (sensitivity and specificity of 0.92 and 0.47 respectively [4]) and the PECARN CPG (sensitivity and specificity of 0.98 and 0.60 respectively [3]), appear to offer this profile when assessed in other settings. However both include procalcitonin testing, which is not currently recommended for use in the UK [26]. Of the tailored approaches available in our setting (NICE NG143, and the proposed BSAC CPG), both demonstrated higher specificities than NG51 (0.09 and 0.14 respectively); however any benefit was offset by an associated drop in sensitivity to 0.91 and 0.82 respectively. These latter tools also performed unfavourably in comparison to StepbyStep and the PECARN CPG $[3,4]$.

Clinician performance accuracy appeared to confer better balance in the sensitivity vs specificity trade-off than national guidance. The overall sensitivity of clinician practice was 0.96, displaying no significant difference to the most cautious guidance (NG51). Despite this remarkably high sensitivity clinicians managed to avoid administering parenteral antibiotics to all infants with a specificity of 0.27 . This was significantly $(p<0.0001)$ higher than any CPG studied. The reasons for this are unknown and require further research. It is possible that clinicians were combining clinical experience with the underpinning principles provided by NICE guidance.

In this study the vast majority of infants were admitted (90\%) and most received parenteral antibiotics (76\%) despite the majority of infants not having a serious bacterial infection. In addition $59 \%$ of infants underwent a lumbar puncture with each infant undergoing an average of three attempted lumbar punctures before a sample of cerebrospinal fluid could be collected. This would suggest that the implementation of a new CPG that could correctly and reliably identify low risk infants could reduce length of stay, improve antimicrobial stewardship and reduce the need for invasive procedures such as lumbar puncture. There is however, very 
limited evidence available to demonstrate the real-world effect of implementing tailored CPGs in this cohort [27]. Further research is required to determine if clinicians would comply with any new guidance and if this would alter outcomes in a meaningful way i.e. reduce the pain and distress from unnecessary procedures or safely reduce the use of parenteral antibiotics.

The univariate and multivariable analysis of clinical features failed to demonstrate any clear predictors of $\mathrm{SBI} / \mathrm{IBI}$ in this cohort, in keeping with similar other international studies [3-9]. The combination of appearing well and having received a vaccination within the preceding 24 hours did however, confer lower risk. Of the 70 infants that had received vaccination within the preceding 24 hours, only two had SBI (both UTIs). Well appearing infants presenting within 24 hours of vaccination may represent a lower risk group suitable for limited investigation and observation without the need for parenteral antibiotics.

\section{Summary}

This study demonstrates that the rates of SBI/IBI amongst young febrile infants presenting to UK and Irish hospitals is $14 \%$, similar to international estimates from similar populations. Of the three CPGs studied NICE NG51 represents the safest approach but requires all infants to receive parenteral antibiotics. NICE NG143 and BSAC offered a more tailored approach but will classify some infants with SBI as low risk. If NICE NG143 or BSAC guidance are to be used safely then a period of observation or close follow-up in the community is required for those identified as low risk.

\section{Strengths/Limitations}

The strengths of this study are that it is large study including a number of sites from across the UK and Ireland and the first to attempt to validate the NICE and BSAC clinical practice guidelines. There were no specific exclusion criteria in this study as NICE and BSAC guidance do not exclude any specific groups from their guidance. The findings should however, be interpreted with extreme caution when considering infants with a background of extreme 
prematurity, chronic ill health or immunodeficiency.

The limitations are that the study was performed retrospectively and as such will not include all febrile infants that have attended at all sites (It is however, reassuring that the reported rates of $\mathrm{SBI} / \mathrm{IBI}$ are broadly similar to international estimates). The nature of the retrospective data collection will also introduce some bias into the study and with all sites being tertiary level children's hospitals the results less transferrable to non-tertiary settings. The study population was also relatively small with only 12 invasive bacterial infections (IBI) and the study may therefore have been underpowered to reliably identify clinical predictors of IBI. 


\section{What is known about this topic?}

- Febrile infants under 90 days of age are at high risk of serious bacterial infection.

- Identifying infants with serious bacterial infections is challenging creating a dilemma as to who should receive treatment.

- There are a number of different clinical practice guidelines available internationally to direct care and identify higher and lower risk infants. These guidelines utilise procalcitonin testing which is largely unavailable, for this use, in the UK and Ireland.

\section{What this study adds}

- In the UK and Ireland, $14 \%$ of infants aged under 90 days presenting to emergency care with a fever had an underlying serious bacterial infection.

- Infants who appear well and have received a vaccine within the preceding 24 hours are at a very low risk of serious bacterial infection.

- The NICE guidelines NG51 and NG143 and the proposed BSAC guidance demonstrated an inferior performance when compared to validated clinical practice guidelines used internationally. 


\section{Declarations}

1. Ethical approval: National research ethics committee approval was not necessary for this study based on the results from the Health Research Association decisions tool. The study was however registered with, and approved by, research governance offices at the respective sites.

2. Declaration of interests: None declared.

3. Funding: None

4. Authors' contributions: Dr Waterfield, Dr Lyttle, Dr Roland and Dr Maney contributed to the design of the study. Dr Waterfield and Dr McGinn co-ordinated the running of the study including data management and site training. Dr Lyttle and Dr Waterfield designed the electronic CRFs. Dr Lyttle, Dr Maney, Dr Roland, Ms Platt, Dr Durnin and Dr Barrett were site leads. Dr McFetridge and Dr Mitchell provided statistical expertise and performed the statistical analysis. All authors contributed to data collection and the writing of the manuscript.

5. Acknowledgements: We thank all sites and their staff for contributing to this study. We also acknowledge the contributions of; Dr Anna Wallace (data entry), Dr Turlough Bolger (governance approvals), Alex Turner (data entry), Sarah Sheedy (data entry), Mai Baquedano (REDCap support).

6. Data Sharing: All data collected during this study will be available (including data dictionaries) on the Queen's University Belfast database within three months of completion of the study. 


\section{References}

1. McCaig LF, Nawar EW. National Hospital Ambulatory Medical Care Survey: 2004 emergency department summary. Adv Data. 2006 Jun 23;(372):1-29. PMID: 16841785.

2. Woll C, Neuman MI, Aronson PL. Management of the Febrile Young Infant: Update for the 21st Century. Pediatr Emerg Care. 2017 Nov;33(11):748-753. doi: 10.1097/PEC.0000000000001303. PMID: 29095773; PMCID: PMC5679412.

3. Kuppermann N, Dayan PS, Levine DA, Vitale M, Tzimenatos L, Tunik MG, Saunders M, Ruddy RM, Roosevelt G, Rogers AJ, Powell EC, Nigrovic LE, Muenzer J, Linakis JG, Grisanti K, Jaffe DM, Hoyle JD Jr, Greenberg R, Gattu R, Cruz AT, Crain EF, Cohen DM, Brayer A, Borgialli D, Bonsu B, Browne L, Blumberg S, Bennett JE, Atabaki SM, Anders J, Alpern ER, Miller B, Casper TC, Dean JM, Ramilo O, Mahajan P; Febrile Infant Working Group of the Pediatric Emergency Care Applied Research Network (PECARN). A Clinical Prediction Rule to Identify Febrile Infants 60 Days and Younger at Low Risk for Serious Bacterial Infections. JAMA Pediatr. 2019 Apr 1;173(4):342-351. doi: 10.1001/jamapediatrics.2018.5501. PMID: 30776077; PMCID: PMC6450281.

4. Gomez B, Mintegi S, Bressan S, Da Dalt L, Gervaix A, Lacroix L; European Group for Validation of the Step-by-Step Approach. Validation of the "Step-by-Step" Approach in the Management of Young Febrile Infants. Pediatrics. 2016 Aug;138(2):e20154381. doi: 10.1542/peds.2015-4381. Epub 2016 Jul 5. PMID: 27382134.

5. Aronson PL, Wang ME, Shapiro ED, Shah SS, DePorre AG, McCulloh RJ, Pruitt CM, Desai S, Nigrovic LE, Marble RD, Leazer RC, Rooholamini SN, Sartori LF, Balamuth F, Woll C, Neuman MI; Febrile Young Infant Research Collaborative. Risk Stratification of Febrile Infants $\leq 60$ Days Old Without Routine Lumbar Puncture. Pediatrics. 2018 Dec;142(6):e20181879. doi: 10.1542/peds.2018-1879. Epub 2018 Nov 13. PMID: 30425130; PMCID: PMC6317769. 
6. Baker MD, Bell LM, Avner JR. Outpatient management without antibiotics of fever in selected infants. N Engl J Med. 1993;329(20):1437-1441.

doi:10.1056/NEJM199311113292001

7. Baskin MN, Fleisher GR, O'Rourke EJ. Identifying febrile infants at risk for a serious bacterial infection. J Pediatr. 1993 Sep;123(3):489-90. doi: 10.1016/s00223476(05)81769-x. PMID: 8355131.

8. Cruz AT, Mahajan P, Bonsu BK, et al. ; Febrile Infant Working Group of the Pediatric Emergency Care Applied Research Network . Accuracy of complete blood cell counts to identify febrile infants 60 days or younger with invasive bacterial infections. JAMA Pediatr. 2017;171(11):e172927. doi:10.1001/jamapediatrics.2017.2927

9. Dagan R, Sofer S, Phillip M, Shachak E. Ambulatory care of febrile infants younger than 2 months of age classified as being at low risk for having serious bacterial infections. J Pediatr. 1988 Mar;112(3):355-60. doi: 10.1016/s0022-3476(88)80312-3. PMID: 3346773.

10. Herr SM, Wald ER, Pitetti RD, Choi SS. Enhanced urinalysis improves identification of febrile infants ages 60 days and younger at low risk for serious bacterial illness. Pediatrics. 2001;108(4):866-871. doi:10.1542/peds.108.4.866

11. Mintegi S, Bressan S, Gomez B, Da Dalt L, Blázquez D, Olaciregui I, de la Torre M, Palacios M, Berlese P, Benito J. Accuracy of a sequential approach to identify young febrile infants at low risk for invasive bacterial infection. Emerg Med J. 2014 Oct;31(e1):e19-24. doi: 10.1136/emermed-2013-202449. Epub 2013 Jul 14. PMID: 23851127.

12. Lacour AG, Zamora SA, Gervaix A. A score identifying serious bacterial infections in children with fever without source. Pediatr Infect Dis J. 2008 Jul;27(7):654-6. doi: 10.1097/INF.0b013e318168d2b4. PMID: 18536624.

13. Gómez B, Mintegi S, Benito J, Egireun A, Garcia D, Astobiza E. Blood culture and bacteremia predictors in infants less than three months of age with fever without source. Pediatr Infect Dis J. 2010 Jan;29(1):43-7. doi: 
10.1097/INF.0b013e3181c6dd14. PMID: 19934784.

14. Sepsis: recognition, diagnosis and early management. NICE guideline [NG51]. Published: 13 July 2016 Last updated: 13 September 2017. Available at https://www.nice.org.uk/guidance/ng51

15. Fever in under 5s: assessment and initial management. NICE guideline [NG143]. Published: 07 November 2019. Available at https://www.nice.org.uk/guidance/ng143

16. Carolyne Horner, Robert Cunney, Alicia Demirjian, Conor Doherty, Helen Green, Mathew Mathai, Paddy McMaster, Alasdair Munro, Stéphane Paulus, Damian Roland, Sanjay Patel, Paediatric Common Infections Pathways: improving antimicrobial stewardship and promoting ambulation for children presenting with common infections to hospitals in the UK and Ireland, JAC-Antimicrobial Resistance, Volume 3, Issue 1, March 2021, dlab029, https://doi.org/10.1093/jacamr/dlab029

17. Collins GS, Reitsma JB, Altman DG, Moons KG. Transparent reporting of a multivariable prediction model for individual prognosis or diagnosis (TRIPOD): the TRIPOD statement. BMJ. 2015 Jan 7;350:g7594. doi: 10.1136/bmj.g7594. PMID: 25569120.

18. Harris PA, Taylor R, Thielke R, Payne J, Gonzalez N, Conde JG. Research electronic data capture (REDCap)—A metadata-driven methodology and workflow process for providing translational research informatics support. J Biomed Inform [Internet]. 2009 Apr [cited 2019 Oct 17];42(2):377-81. Available from: http://www.ncbi.nlm.nih.gov/pubmed/18929686

19. Samuels M, Wieteska S. Advanced Paediatric Life Support: A Practical Approach to Emergencies, Sixth Edition. John Wiley \& Sons, Ltd. 2016 Feb.

20. The Health Research Authority. Is my study research? Available at http://www.hradecisiontools.org.uk/research/ last accessed 31/05/2021.

21. Toivonen L, Schuez-Havupalo L, Karppinen S, Waris M, Hoffman KL, Camargo CA, Hasegawa K, Peltola V. Antibiotic Treatments During Infancy, Changes in Nasal Microbiota, and Asthma Development: Population-based Cohort Study. Clin Infect 
Dis. 2021 May 4;72(9):1546-1554. doi: 10.1093/cid/ciaa262. PMID: 32170305; PMCID: PMC8096219.

22. Wypych TP, Wickramasinghe LC, Marsland BJ. The influence of the microbiome on respiratory health. Nat Immunol 2019; 20:1279-90.

23. Fujimura KE, Sitarik AR, Havstad S, Lin DL, Levan S, Fadrosh D, Panzer AR, LaMere B, Rackaityte E, Lukacs NW, Wegienka G, Boushey HA, Ownby DR, Zoratti EM, Levin AM, Johnson CC, Lynch SV. Neonatal gut microbiota associates with childhood multisensitized atopy and T cell differentiation. Nat Med. 2016 Oct;22(10):1187-1191. doi: 10.1038/nm.4176. Epub 2016 Sep 12. PMID: 27618652; PMCID: PMC5053876.

24. Arrieta MC, Stiemsma LT, Dimitriu PA, Thorson L, Russell S, Yurist-Doutsch S, Kuzeljevic B, Gold MJ, Britton HM, Lefebvre DL, Subbarao P, Mandhane P, Becker A, McNagny KM, Sears MR, Kollmann T; CHILD Study Investigators, Mohn WW, Turvey SE, Finlay BB. Early infancy microbial and metabolic alterations affect risk of childhood asthma. Sci Transl Med. 2015 Sep 30;7(307):307ra152. doi: 10.1126/scitransImed.aab2271. PMID: 26424567.

25. Toivonen L, Hasegawa K, Waris M, Ajami NJ, Petrosino JF, Camargo CA Jr, Peltola V. Early nasal microbiota and acute respiratory infections during the first years of life. Thorax. 2019 Jun;74(6):592-599. doi: 10.1136/thoraxjnl-2018-212629. Epub 2019 May 10. PMID: 31076501.

26. Procalcitonin testing for diagnosing and monitoring sepsis. Published: 13 July 2016 Last updated: 13 September 2017. Available at https://www.nice.org.uk/guidance/dg18

27. Foster LZ, Beiner J, Duh-Leong C, Mascho K, Giordani V, Rinke ML, Trasande L, Wiener E, Rosenberg RE. Implementation of Febrile Infant Management Guidelines Reduces Hospitalization. Pediatr Qual Saf. 2020 Jan 22;5(1):e252. doi: 10.1097/pq9.0000000000000252. PMID: 32190797; PMCID: PMC7056289. 
Figure 1: Flow diagram of participants included in the study 
Table 1: Recruitment by site

SITE

PARTICIPANTS BACTERIAL

BACTERAEMIA

URINARY

TRACT

MENINGITIS

INFECTION

\begin{tabular}{l|cc}
\hline BELFAST & 45 & 0 \\
BRISTOL & 90 & 0 \\
DUBLIN & 88 & 1 \\
GLASGOW & 111 & 2 \\
LEICESTER & 151 & 2 \\
LONDON & 70 & 0 \\
TOTAL & 555 & 5
\end{tabular}

$\begin{array}{cc}8 & 9 \\ 9 & 10 \\ 13 & 14 \\ 12 & 17 \\ 12 & 16 \\ 12 & 12 \\ 66 & 78\end{array}$

Table 2: Serious/Invasive bacterial infections

Diagnosis

Bacterial meningitis (5)

$\begin{array}{ll}\text { Bacteraemia (7) } & \text { 1x Group B streptococcus } \\ & 5 \times \text { Escherichia Coli } \\ & 1 \times \text { Neisseria meningitidis B } \\ \text { Urinary tract infection (66) } & \\ & 45 \times \text { Escherichia Coli } \\ & 7 x \text { Enterococcus } \\ & 3 \times \text { Pseudomonas } \\ & 3 \times \text { Klebsiella } \\ & 8 x \text { Other }\end{array}$

1x Group B streptococcus

1x Group A streptococcus

$1 x$ Streptococcus pneumoniae

$1 \mathrm{x}$ Enterococcus

1x Escherichia Coli

Table 3: Performance of CPGS (Imputed Data)

\begin{tabular}{llrccccc}
\hline Guideline & Outcome & SBI & No SBI & $\begin{array}{c}\text { Sensitivity } \\
(\mathbf{9 5 \%} \text { CI) }\end{array}$ & $\begin{array}{c}\text { Specificity } \\
(\mathbf{9 5 \%} \text { CI) }\end{array}$ & $\begin{array}{c}\text { PPV } \\
(\mathbf{9 5 \%} \text { CI) }\end{array}$ & $\begin{array}{c}\text { NPV } \\
(\mathbf{9 5 \%} \text { CI) }\end{array}$ \\
\hline Clinician Practice & Treat & 75 & 346 & 0.96 & 0.27 & 0.18 & 0.98 \\
& Do Not Treat & 3 & 131 & $(0.89$ to 0.99$)$ & $(0.24$ to 0.32$)$ & $(0.14$ to 0.22$)$ & (0.94 to 1.00$)$ \\
NG51 & Treat & 78 & 477 & 1 & 0 & 0.14 & N/A \\
& Do Not Treat & 0 & 0 & $(0.95$ to 1.00$)$ & $(0.00$ to 0.01$)$ & $(0.11$ to 0.17$)$ & (0.00 to 1.00$)$ \\
\multirow{2}{*}{ NG143 } & Treat & 71 & 433 & 0.91 & 0.09 & 0.14 & 0.86 \\
& Do Not Treat & 7 & 44 & $(0.82$ to 0.96$)$ & $(0.07$ to 0.12$)$ & $(0.11$ to 0.17$)$ & $(0.74$ to 0.94$)$ \\
BSAC & Treat & 64 & 411 & 0.82 & 0.14 & 0.13 & 0.82 \\
& Do Not Treat & 14 & 66 & $(0.72$ to 0.90$)$ & $(0.11$ to 0.17$)$ & $(0.11$ to 0.17$)$ & $(0.72$ to 0.90$)$ \\
\hline
\end{tabular}


Table 4: Univariate analysis of variables (Fisher's Exact for categorical variables, MannWhitney $U$ for continuous variables). Number and (\%) with feature shown for categorical variables and median for continuous variables unless otherwise stated.

\begin{tabular}{|c|c|c|c|c|}
\hline Variable & Complete Data N(\%) & $\begin{array}{l}\text { Without SBI } \\
\qquad N(\%)\end{array}$ & $\begin{array}{c}\text { With SBI } \\
\qquad N(\%)\end{array}$ & $P$ Value \\
\hline Gender (Male) & $555(100)$ & 275(57.7) & $50(64.1)$ & 0.32 \\
\hline Age in days (median and interquartile range) & $555(100)$ & $56(34$ to 70$)$ & $44(22$ to 69$)$ & 0.030 \\
\hline Temperature (median and interquartile range) & $555(100)$ & $38.3(38.1$ to 38.7$)$ & $38.4(38.2$ to 38.7$)$ & 0.087 \\
\hline Received vaccine in preceding 24 hours & $555(100)$ & $76(15.9)$ & $3(3.8)$ & 0.0027 \\
\hline Normal colour & $555(100)$ & $138(28.9)$ & 23(29.5) & 0.89 \\
\hline Alert/responding to social cues & $555(100)$ & $152(31.9)$ & 23(29.5) & 0.79 \\
\hline Normal Cry & $555(100)$ & $70(14.7)$ & 11(14.1) & 1.00 \\
\hline Normal skin/eyes & $555(100)$ & $90(18.9)$ & 18(23.1) & 0.44 \\
\hline Moist mucous membranes & $555(100)$ & $105(22.0)$ & 23(29.5) & 0.14 \\
\hline Appears well & $555(100)$ & $91(19.1)$ & $7(9.0)$ & 0.036 \\
\hline Decreased activity & $555(100)$ & $102(21.4)$ & $23(29.5)$ & 0.14 \\
\hline Tachycardia & $555(100)$ & $370(77.6)$ & $60(76.9)$ & 0.88 \\
\hline Prolonged capillary refill time & $555(100)$ & $68(14.3)$ & $19(24.4)$ & 0.029 \\
\hline Reduced feeding & $555(100)$ & 213(44.7) & $43(55.1)$ & 0.088 \\
\hline Reduced wet nappies & $555(100)$ & $38(8.0)$ & $7(9.0)$ & 0.82 \\
\hline Mottled/ashen/pale/blue colour & $555(100)$ & $175(36.7)$ & $34(43.6)$ & 0.25 \\
\hline Not responding to social cues & $555(100)$ & $31(6.5)$ & $5(6.4)$ & 1.000 \\
\hline Appears unwell & $555(100)$ & $65(13.6)$ & $11(14.1)$ & 0.86 \\
\hline Lethargic on examination & $555(100)$ & $11(2.3)$ & $4(5.1)$ & 0.25 \\
\hline Respiratory symptoms & $555(100)$ & $113(23.7)$ & $20(25.6)$ & 0.77 \\
\hline Dehydration & $555(100)$ & $23(4.8)$ & $4(5.1)$ & 0.78 \\
\hline Non-blanching rashes & $555(100)$ & $20(4.2)$ & $2(2.6)$ & 0.75 \\
\hline Meningism & $555(100)$ & $25(5.2)$ & $7(9.0)$ & 0.19 \\
\hline
\end{tabular}


Table 5: Investigations performed and comparisons between cohorts

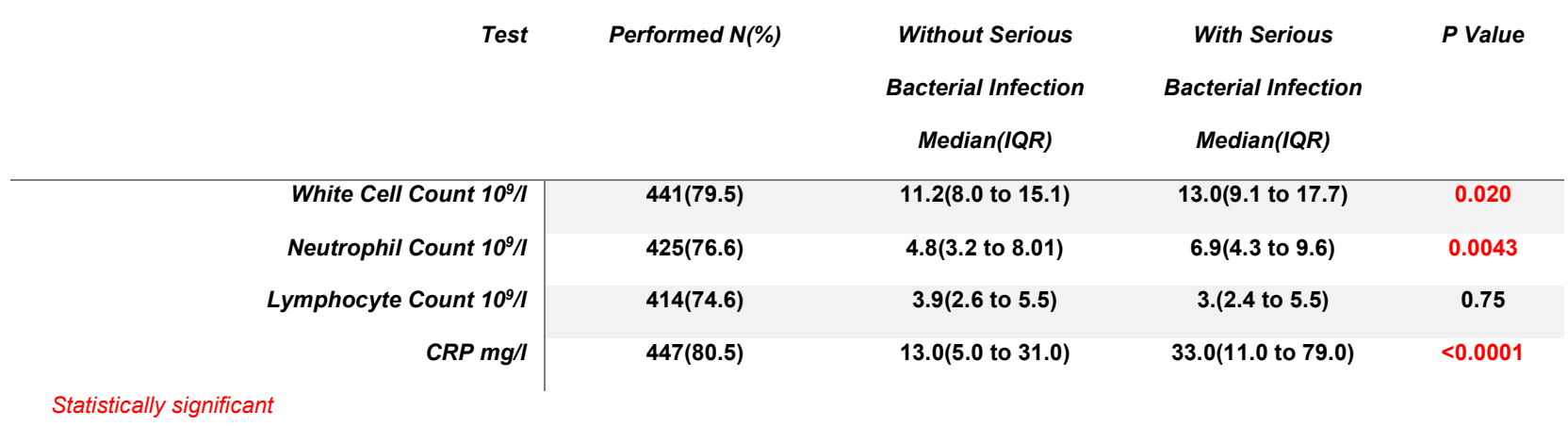

